\section{THE ROLE OF THE INTERNET IN CHANGING KNOWLEDGE ECOLOGIES}

\author{
Bill Cope y Mary Kalantzis \\ University of Illinois at Urbana-Champaign, USA \\ Research Professor \\ Department of Educational Policy Studies \\ College of Education \\ University of Illinois, Urbana-Champaign \\ 326 Education \\ 1310 S. Sixth Street, $M C-708$ \\ Champaign, IL 61820 USA \\ billcope@uiuc.edu
}

RESUMEN: Más allá de lo que suele admitirse, el moderno sistema de conocimiento científico y universitario es una creación de la sociedad de la imprenta. Antes de llegar el siglo XXI, la imprenta era el canal de comunicación académica. Entonces, de manera bastante repentina con el cambio de siglo, los textos digitales empezaron a sustituir a la imprenta como el medio principal por el que los académicos acceden al conocimiento. Este artículo analiza algunas de las consecuencias de este cambio. ¿Hasta qué punto las tecnologías digitales de representación y comunicación reproducen los sistemas de conocimiento utilizados en el último medio milenio de historia de la moderna universidad? ¿ 0 quizás la interrumpen y la transforman? Para responder a esta pregunta, este articulo explora aspectos clave de las transformaciones contemporáneas, no sólo en la forma textual de las representaciones digitales, sino también la emergencia de formas sociales que la digitalización refleja, permite y apoya. A esto llamamos la "web social", una expresión que utilizamos para describir el tipo de relaciones con el conocimiento y la cultura que está emergiendo en esta era dominada por la interconexión computacional. ¿Cuáles son entonces los impactos y el potencial de estos cambios sobre los procesos de formación de nuevo conocimiento?

PALABRAS CLAVE: Internet, comunicación académica, sistemas del conocimiento.

\section{EL PAPEL DE INTERNET EN LAS CAMBIANTES ECOLOGÍAS DEL CONOCIMIENTO}

ABSTRACT: To a greater extent than is often acknowledged, the modern scientific and university-based knowledge system is a creature of the society of the printing press. Until the turn of the twentyfirst century, print was the medium of scholarly communication. Then, quite suddenly at the turn of the twenty-first century, digital text begins to displace print as the primary means of access to the knowledge of academicians. This article explores some of the consequences of this change. To what extent do digital technologies of representation and communication reproduce the knowledge systems of the half-millennium long history of the modern university or do they disrupt and transform them? To answer this question, this article will explore key aspects of contemporary transformations, not just in the textual forms of digital representation, but the emerging social forms that digitisation reflects, affords and supports. This we call the "social web", a term we use to describe the kinds of relationships to knowledge and culture that are emerging in the era of pervasively interconnected computing. What, then, are the impacts and potentials of these changes on the processes of formation of new knowledge?

KEY WORDS: Internet, scholarly communication, knowledge systems.

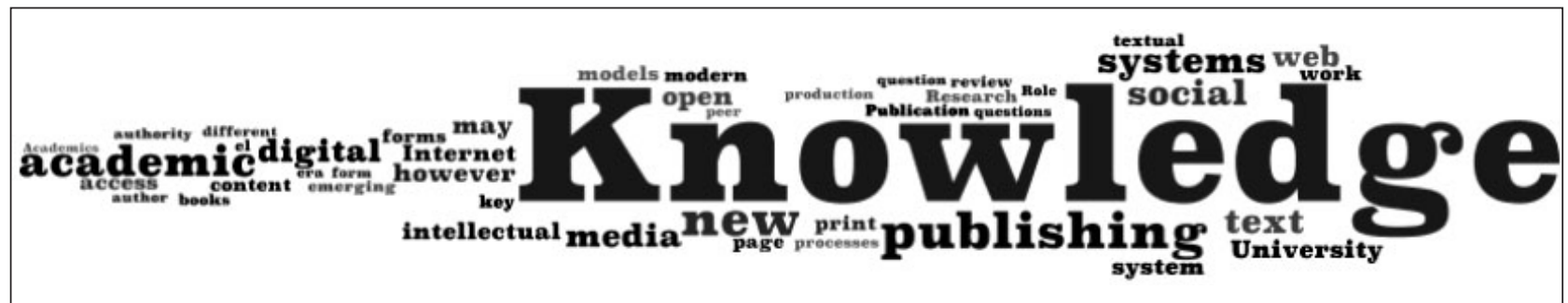




\section{The Social Web}

The first printed book, Gutenberg's 1452 Bible, had no title page, no contents page, no page numbering. Extant copies show the signs of ecclesiastical, manuscript culture - the beautifully illuminated marginalia which, until the era of print, gave the written word an aura of authority that raised it above the spoken word of everyday experience. It took another fifty years for the textual architecture of the printed word to take its modern form, and with it, new forms of textual authority.

By 1500, the end of the period of "incunabula", eight million books had been printed. It was not until then that printed text came to be marked by the structures of graduated type and spatial page design, and the information hierarchies of chapter headings, section breaks and subheadings. Navigational devices were added in the form of tables of contents and running heads. Alphabetically ordered indexes were added. And the text was divided into uniform and easily discoverable units by means of the most under-rated and revolutionary of all modern information technologies - the page number (Eisenstein, 1979; Febvre and Martin, 1976).

These textual forms became the ground for representations of knowledge in its characteristically modern form. Petrus Ramus, a professor at the University of Paris in the mid sixteenth century, could be regarded as the inventor of the modern textbook, laboriously laying out in print the content of domains of knowledge by way of a sectionalised knowledge taxonomy. Eleven hundred editions of Petrus Ramus's texts were published between 1550 and 1650. Walter Ong credits Ramus with no intellectual originality in the content of the texts', but with an ingenious sense for the emerging epistemic order in which knowledge was analytically laid out and spatially ordered, replacing the authority and pedagogy of rhetoric and dialogue with the atomistically compartmentalised and formally schematised knowledge of modern academe (Ong, 1958).

Also characteristic of the textual forms of the emerging print culture was the premium it placed on accuracy, from the standardisation of spelling in vernacular languages, to the processes of editing, proofing and correction. Even after printing, errata were used to correct the text, and text was further corrected from edition to edition - a logic intrinsic to the fastidiousness for detail and empirical verity which marked the emerging lifeworlds of the thinkers and teachers of the early modern academy.

Not merely textual, printed texts came to be located in an intertextual universe of cross-referencing. The announcement of author and title did not just mark the beginning of a work. It situated that work and its author in a universe of other texts and authors, and marked this with the emerging conventions of librarianship, citation and bibliography. Moving away from the rhetorical tradition, authors used footnotes and referencing, not only as a sign of the erudition upon which authoritative text was necessarily grounded, but also to distinguish the author's distinctive and ostensibly original voice, from those of the textual authorities or research data upon which they were relying (Grafton, 1997).

No longer simply a matter of identification of authorial voice, the new social conventions of authorship became the boundary markers of private intellectual property, the copyright of authors as originators ideas being embodied in specific forms of words. Knowledge as intellectual property expressed in written text, owned by the individual author and alienable as commodity, was to be found in incipient forms as early as fifteenth century Venice (Rose, 1993).

This regime of textual knowledge became a key foundation of the modern university, a point of clear break in from its monastic origins. It was a both symptom and a an enabler in the development of characteristically modern ways of attributing human origins to ideas and of ascribing authority to these ideas.

The purpose of this quick sketch is to consider what is new and not new about the emerging regime of digitised text. Widespread digitisation of parts of the text production process began in the 1970s with phototypesetters that were driven by rudimentary word processing programs (Cope and Kalantzis, 2001). During the 1980s and 1990s, word processing and desktop publishing became near-universal tools of authorship. Academics who had previously handwritten their articles and books, passing them on to typists, started to spend a good part of their working days keyboarding digital text. The logic of their work, however, remained to a large degree within the Gutenberg orbit, marking up the information architectures of their text in 
the typographic mode, designed to be printed or pseudoprinting in the form of PDF (Portable Document Format) digital replicas of the printed page.

Three decades into the digitisation process, we may well still be in an era of what Jean-Claude Guédon calls "digital incunabula", in which the full potentialities of digital text have barely been explored, let alone exploited (Guédon, 2001). Information is locked up in PDFs which are designed for printing out less than the functionalities of search, access and copying offered by more advanced digitisation technologies. Such texts-for-print are not marked up by structure and semantics, so even the best search mechanisms offer little more than what can be achieved through word collocation algorithms, far less adequate in some crucial respects than the traditions of indexing and cataloguing from the era of print.

Moreover, some things which are purported to be new about digital text, are not so new at all. For all its apparent novelty, "hypertext" is nothing other than a version of the process of referencing to be found in the tradition of page numbering and catalogue listing established over the past five centuries. What is the hyptertextual link other than a way of making the same old distinction of individual authorship, delineating the boundaries between one piece of intellectual property and the next, and a sign of deference to the authorities on which a text is based?

As for the much-vaunted novelty of the "virtual", what more is this than a reincarnation of the modes of representation of distant people, places and objects that made books so alluring from the moment they became cheaply and widely accessible? Also, books and their distribution systems, no less than today's networked communities, allowed the creation of dispersed communities of expertise (Cope and Kalantzis, 2004)?

Some things about the world of digital communications, however, may turn out to be very different from the world of printed text. Just how different remains to be seen, and the full impact may take decades to become clear. Or it may happen sooner.

Several features of the new communications environment stand out. One is a change to the economies of cultural and epistemic scale. Whilst something like one thousand copies need to be sold to make a print run viable, there is no difference in the cost of one person or a thousand reading a web page, or a print-on-demand book. The immediate consequence is that the amount of published and accessible content is rapidly growing and the average number of copies accessed of each academic work is declining (Waters, 2004). These are ideal conditions for the development of every more finely grained areas of knowledge, cultural perspectives and localised applications of knowledge. So significant is this change, that knowledge itself may changes. What is the enduring validity of universal and universalising perspectives? How do they accommodate the particular? How does the local connect with the global? Furthermore, with the development of Unicode and machine translation, scholarly communication beyond the local may not for much longer have to be expressed in the language of global English, and if it is, it is in the specialised discourses of academic technicality less dependent for their aura of reliability on the "good style" of native English speakers.

Another key feature is the intrinsic multimodality of the new media. The elementary modular unit of text manufacture in the Gutenberg (and then ASCII) era was the character. Digital texts make written words and images of the same stuff, pixels, and sound of the same stuff as pixels - the zeros and ones of semiconductor circuitry. In everyday life, we have experienced this radical conflation of modes throughout the media, from illustrated books and journals (previously, lithographic processes as a simple matter of technical convenience meant, that images were mostly placed on pages of their own), to video, to the internet. Academe, however, has stayed steadfastly wedded to text, with the increasing incursion, however, of diagrams and images into the text (Kress, 2003). Will the new media destablise the traditional textual forms of book an article, or essay, paper and thesis? In what other ways might knowledge be represented today, and particularly in the areas of the sciences, the arts (Martin and Booth, 2007) and design?

Perhaps most significant, however, is what we call a shift in the balance of textual agency between the author and reader (Kalantzis and Cope, 2008). Here are some examples and symptoms of this change. Whereas print encyclopedias provided us definitive knowledge constructed by experts, Wikipedia is constructed, reviewed and editable by read- 
ers and includes parallel argumentation by reader-editors about the "objectivity" of each entry. Whereas a book was resistant to annotation (the size of the margins and a respect for its next reader), new reading devices and formats encourage annotation in which the reading text is also a (re)writing text. Whereas the diary was a space for time-sequenced private reflection, the blog is a place for personal voice which invites public dialogue on personal feelings. Whereas a handwritten or typed page of text could only practically be the work of a single creator, "changes tracking", version control and web document creation such as Google Docs make multi-author writing easy and collaborative authorship roles clear. Whereas novels and TV soaps had us engaging vicariously with characters in the narratives they presented to us, video games make us central characters in the story where we can influence its outcomes. Whereas broadcast TV had us all watching a handful television channels, digital TV has us choosing one channel from amongst thousands, or interactive TV in which we select our own angles on a sports broadcast, or making our own video and posting it to YouTube or the web. Whereas broadcast radio gave listeners a programmed playlist, every iPod user creates their own playlist (Kalantzis, 2006). We call this rebalancing of agency, this blurring of the boundaries between authors (and their authority) and readers (and their reverence), "the social web". If print limited the scope for dialogue, the electronic communications web opens up that scope.

Each of these new media is reminiscent of the old. In fact, we have eased ourselves into the digital world by using old media metaphors - creating documents or files and putting them away in folders on our desktops. We want to feel as though the new media are like the old. In some respects they are, but in other respects they are proving to be quite different.

The earlier modern regime of communications used metaphors of transmission - for television and radio literally, but also in a figurative sense for books, curricula, public information, workplace memos and all manner of information and culture. This was an era when bosses bossed, political leaders heroically led (to the extent even of creating fascisms, communisms and welfare states for the ostensible good of the people), and personal and family life (and "deviance") could be judged against the canons of normality. Not only have things changed in today's every- day life - the most advanced of contemporary workplaces devolve responsibility to teams and ask workers to buy into the corporate culture. Neoliberal politics tells people give up their reliance on the state and to take responsibility into their own hands. Diversity rules in everyday life, and with it the injunction to feel free to be true to your own identity.

Things have changed in an homologous fashion in the social relations of representation. Audiences have become users. Readers, listeners and viewers are invited to talk back to the extent that they have become media co-designers themselves. The division of labour between the creators of culture or knowledge and their consumers has been blurred. The direction knowledge flows is changing. In fact, the flows are now multifarious and in many directions. Consumers are also creators, and creators, consumers. Knowledge and authority are more contingent, provisional, and conditional - based relationships of "could" rather than "should". They are more open to contestation and to critical reading on the basis of personal experience and voice. Knowledge and culture, as a consequence, become more fluid.

This is what we mean by a shift in the balance of agency, from a society of command and compliance to a society of reflexive co-construction. It might be that the workers creating bigger profits for the bosses, that neoliberalism "naturally" exacerbates disparities in social power, and that proclamations of diversity are a way of putting a positive gloss on inequality. The social outcomes, indeed, may at times be disappointingly unchanged or the relativities even deteriorating. What has changed is the way these outcomes are achieved. Control by others has become self-control; compliance has become self-imposed. New media are one part of this broader equation. The move may be primarily a social one, but the technology has provided new affordances and social aspiration has helped us image uses for available technologies even beyond the imaginings of their inventors.

Where does this leave the university as a source of epistemic authority? What is the status of Wikipedia, written by tens of thousands of unnamed persons who may or may not have passed the credentialing hurdles of higher education, the authority of individual expert voice or institutional credentials? What is the status of an academic's 
blog? How do we reference mini-lectures on YouTube, and measure the validity of one YouTube video against the next or a refereed article? How do we assess practice-based and multimodal theses, publications and exhibitions?

The means of production of meaning in the social web are also deceptively the same, and different, to what has preceded. Eschewing the Gutenberg look-alikes of word processing, desktop publishing and postscript files is a new tradition of semantic and structural markup (as opposed to visual markup, for one rendering). This tradition originated in the IBM labs of the 1960s as Standard Generalized Markup Language, but rose to widespread prominence with Berners-Lee's HTML in the early 1990s, and subsequent refinement as XML and more recently the Resource Definition Framework of the "Semantic Web" (Cope and Kalantzis, 2004; Cope and Phillips 2006). This second generation internet was dubbed Web. 2.0 in 2003 (0'Reilly, 2005). It is manifest in widespread application web-based social networking technologies including wikis, weblogs, podcasts and syndication feeds. In the words of the un-named author or authors of the Wikipedia Web 2.0 entry, it is also a "social phenomenon embracing an approach to generating and distributing Web content itself, characterized by open communication, decentralization of authority, [and] freedom to share and re-use".

\section{Distributed Knowledge Systems}

Universities today face significant challenges to their historical role as producers of socially privileged knowledge. More knowledge is being produced by corporations than was the case in the past. More knowledge is being produced in the broadcast media. More knowledge is being produced in the networked interstices of the social web, where knowing amateurs mix with academic professionals, in many places without distinction of rank. In these places, the logics and logistics of knowledge production are disruptive of the traditional values of the University - the for-profit, protected knowledge of the corporation; the multimodal knowledge of audiovisual media; and the "wisdom of the crowd" which ranks knowledge and makes it discoverable through the internet according to its popularity.
The new, digital media raise fundamental questions for the University. How can it connect with the shifting sites and modes of knowledge production? How can it stay relevant? Are its traditional knowledge-making systems in need of renovation? What makes academic knowledge valid and reliable, and how can its epistemic virtues be strengthened to meet the challenges of our times? How can the University meet the challenges of the new media in order to renovate the disclosure and dissemination systems of scholarly publishing? How can the University connect with the emerging and dynamic sources of new knowledge formation outside its traditional boundaries?

To a greater extent than is frequently acknowledged, the rituals and forms of print publishing were integral to the modern republic of human and scientific knowledge. Publication was contingent upon peer review, it represented a point of disclosure in which other scientists could replicate findings or other humanists could verify sources. Until publication, academic knowledge is without status, unassimilable into the body of knowledge that is the discipline and without teachable value. Publication is an integral part of the academic knowledge system.

Pre-publication, peer review as a method of scientific knowledge validation began to evolve from the seventeenth century, with Oldenburg's editorship of the Philosophical Transactions of the Royal Society (Biagioli, 2002; Guédon, 2001; Peters, 2007; Willinsky, 2006). Post-publication, bibliometrics or citation analysis emerged as measure of ranking of the value of a published piece. The more people who cited an author and their text, the more influential that person and their work must have been on the discipline. This thinking was refined in the work of Eugene Garfield and his Institute for Scientific Information.

The system of academic publishing, however, reached a now well-documented crisis point at the beginning of the twenty-first century. The bulk of academic journal and book publishing was still dominated by commercial publishers producing to the economies and production logics of print - even their electronic versions were by and large in print-reproduction PDF form. The commercial publishers came under increasing fire for the slowness of their publication processes contrasted with the immediacy of the web, the relative closure of their networks of editorial control contrasted with the more democratic open-ness of

ARBOR CLXXXV 737 mayo-junio [2009] 521-530 ISSN: 0210-1963

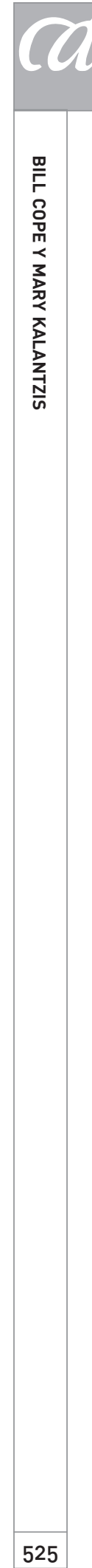

525 
the web, but most importantly for the rapidly increasing cost of journal subscriptions and book contrasted to the free content on the web (Bergman, 2006; Peters, 2007; Stanley, 2007; Willinsky, 2006). The background to this growing critique was one of the most remarkable phenomena of the evolving world of the internet, and that is freely accessible intellectual property in the form of software code (Raymond, 2001; Stallman, 2002; Williams, 2002), content tagged with Creative Commons licenses (Benkler, 2006; Lessig, 1999; Lessig, 2001; Lessig, 2004) and, more specific to the case of academic knowledge, the rise of open access journals (Bergman, 2006; Peters, 2007).

These developments in an economic domain that Benkler calls "social production", are not, however, without their own difficulties. John Willinsky speaks lyrically of a return to the days when authors worked beside printers to produce their books (Willinsky, 2006). However, academics do not have all the skills or resources of publishers. Nor is playing amateur publisher necessarily the best use of their time. The new economy of social production, moreover, is removing the economic basis for publishing as a form of employment and as a way of helping fund professional associations and research centres which have historically gained revenue from the sale of periodicals and books. Tens of thousands of people used to work for encyclopedia publishers, even if some of the jobs, such as that of the proverbial door to door salesperson, were less than ideal. Everybody who writes for Wikipedia has to have another source of income. What would happen to the significantly sized global scholarly publishing industry if academics assumed collective and universal responsibility for self publishing, and industry not supporting in 2004 a reported 250,000 employees worldwide with a \$US65 billion turnover (Peters, 2007)?

Open-access, moreover, does not necessarily reduce the points of closure in academic publishing: its English language and developed world bias; the self-replicating logic which gives visibility to established journals and the insider networks that support them; its bias to the natural sciences at the expense of the social sciences and humanities; its valuing of journal articles over books; the intrinsic lack of rigour of most refereeing, without reference to explicit criteria for valid knowledge; and its logic of ranking in which academic popularity ranks ahead of academic quality, and self- and negative citation carries the same weight as positive external citation (Peters, 2007).

The internet in its initial forms, in fact, perpetuates many of precisely these deficiencies. Google is the brainchild of the son of a professor who translated Garfield's citation logic into the page rank algorithm which weights a page according to its "backward links", or the people who have "cited" that page by linking to it. When is such a process unhelpful populism, mob rule even, in the newly democratised republic of knowledge? And what do we make of a knowledge system in which even the wisdom of the crowd can be trumped by the wisdom of the sponsored link?

In 1965, J. C. R. Linklider wrote of the deficiencies of the book as a source of knowledge, and imagined a future of "procognitive systems" in the year 2000 (Linklider, 1965). He was anticipating a completely new knowledge system. That system is not with us yet. We are still in the era of digital incunabula.

In semantic publishing technologies, however, we see possibilities not yet realised, in which all the world's knowledge is marked up within developing disciplinary discourses and meaningfully accessible. In the social web, we can gain an inkling of dialogical processes in which academics, professionals and amateurs may advance knowledge more rapidly, take greater intellectual risk, and create more creatively divergent and globally distributed bodies of knowledge and theoretical paradigms than was possible in the slower and more centralised knowledge production systems of print publishing.

If it is the role of the University to produce deeper, broader and more reliable knowledge than is possible in everyday, casual experience, what do we need to do to deepen this tradition rather than to surrender to populism? What needs to be done about the knowledge validation systems of peer review and the dissemination systems academic publishing? These are fundamental questions at this transitionary moment. Their answers will not just involve new publishing processes. They will entail the creation of new systems of knowledge production, validation and distribution. 


\section{Emerging Knowledge Ecologies: An Agenda for Transformation}

The internet has undoubtedly had a disruptive influence on the knowledge creation system in which traditional academic publishing had previously been dominant. However, at the beginning of the twenty-first century, there appears to be a bifurcation of alternatives, each with its own limitations, neither of which realizes the now-evident potentials of the new, digital media.

On the one hand, there is commercial publishing, dominated by half a dozen multinational conglomerates which still use the traditional publishing workflow. To be sure, electronic editions are now available alongside print. However, the basic publishing infrastructure has not been altered. Nor have these conglomerates been leaders in technology and publishing innovation. Rather, they have grafted innovations from elsewhere in the universe of internet and digital text onto their existing offerings. As a consequence, their cost structures are very high. The cost of producing an article reported to be about $\$ U S 3,000$. This is inexcusably high when the primary work of quality assessment and content development is with academic peers and editors who are unpaid or paid very little. On the other hand, holding a monopoly position on the titles of journals, the big publishers charge excessively high prices to university libraries for subscriptions, and make unusually high margins of profit in the otherwise highly competitive media sector. They are slow to publish. And individual authors, titles and topics are not particularly visible to internet search because articles are stored behind subscription walls.

On the other hand, open access publishing is bedeviled by problems of resourcing and mostly has to rely on academic volunteerism and enlightened amateurism. It is sometimes forced to develop funding mechanisms which amount to charging by stealth - in the form of author publication fees, "memberships" and institutional subsidies. One could argue, indeed, that the economic basis for the open access knowledge system is a kind of socialism for the affluent - if you work as a professor in a big, well-funded research university, of course you can donate some of your time to publishing. This time, however, has a cost which needs to be factored in. It is a moot point whether this is the best use of the professor's time; however, the key point is that only people in privileged employment will have the time, and also indirectly funded support such as the use of graduate assistants. There are, in other words, key questions about the sustainability and equity of open access business models.

However, apart from the ongoing and far-from resolved debate about business models, open access publishing does not necessarily take us beyond intrinsic limitations of today's academic knowledge systems. The discussion about commercial versus open access models has tended to neglect broader and deeper questions about what we call "academic knowledge ecologies", including questions about content development processes as well as questions of resourcing and sustainability. What kinds of renewal do our academic knowledge systems require in order to improve their quality, effectiveness and value as an integral part of the research and knowledge building infrastructure of a peculiarly "knowledge society"?

What we propose below is an agenda for further discussion, developed in conjunction with colleague Professor Michael Peters here at the University of Illinois. The following ten points represent an agenda for further research. They are also a practical development agenda, suggesting that academic publishing, and the knowledge ecology which it supports, has a long way to go before it fully exploits the affordances of the internet. From the more specific to the more general, the key questions we propose towards the development of future knowledge systems are as follows:

1. Pre-Publication Knowledge Validation: Whether it is commercial publishing or open access, the peer review system is not working as well as it might. Peer review is not universal and it is not always clear which journals are peer reviewed and which are not. In fact, the shift to digital repositories and rapid publication may be reducing the proportion of peer reviewed academic articles. In both open access and commercial models, however, editors have disproportionate influence which may at times affect their quality as knowledge systems: choosing reviewers who are likely to be sympathetic or unsympathetic to a particular article; general lack of a systematic, consistent and criterion-referenced review processes; and an absence of reflexivity now characteristic of online "social networking" environments - who reviews the reviewers

ARBOR CLXXXV 737 mayo-junio [2009] 521-530 ISSN: 0210-1963

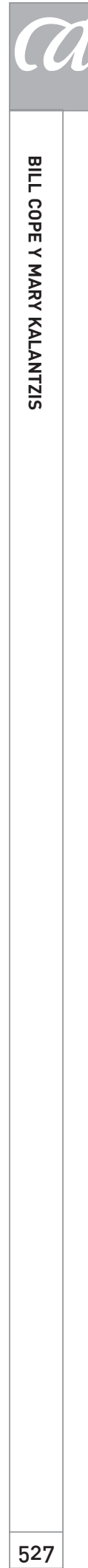


(metamoderation)? and how does the author enter dialogue with the reviewer? The key point here is that the current peer review system has a tendency at times to conserve the boundaries of closed knowledge networks and to create an intellectual inertia which works against the publication of cross-disciplinary, substantially innovative or potentially paradigm-altering thinking. How, then, do we develop publication and knowledge systems which are more open and more reflexive? What can be learnt from the logics of the "social web".

2. Post-Publication Knowledge Validation: Today's systems of bibliometrics and impact assessment tend to favour traditional publishing models. Current validation processes (e.g. ISI/Web of Knowledge) are not transparent and probably not reliable. They have notable and well-documented flaws, including self-citation and negative citation counts. The system neglects books and other media. Rejection rates are an arbitrary relation to the number of articles a journal publishes per year and the generality of its scope. Knowledge is measured by a form of "popularity" rating which works against small, specialised and emerging fields. Models of "webometrics" are now appearing, but they are still crude. We need investigate and develop more reliable ways of assessing the quality and impact of published knowledge. Furthermore, post publication, there is little opportunity for new and revised editions of articles to be published based on the ongoing dialogue of post-publication review. Post-publication knowledge validation needs to become more reflexive so that qualitative impact assessment feeds back into the knowledge system. (At the moment the main function it services is as a career performance indicator.) Through an iterative process, readers could become more closely in the creation and refinement of knowledge.

3. Sustainability: Beyond the open access/commercial publishing dichotomy, there is a question of resourcing models and sustainability. Academics' time is not best spent as amateur publishers. The key research question is here how does one build sustainable resourcing models which neither require cross-subsidy of academics' time, nor the unjustifiable and unsustainable costing and pricing structures of the big publishers?
Here, the key challenge is to develop new business models.

4. Intellectual property: How does one balance academics' and universities' interest in intellectual property with the public knowledge interest? At times, the "gift economy" supports a "theft economy" in which private companies profit from the supply content provided at no charge. Search companies, copy content without permission or payment, and make money from advertising alongside this content. The key question here is, how does one establish an intellectual property regime which sustains intellectual autonomy, rather than a "give away" economy which may at times undervalue the work of the academy? When and to what extent are open access and "commons" approaches to intellectual property appropriate and functional to creating socially productive knowledge systems? When are conventional licenses appropriate?

5. Distributed knowledge: How do we open out academic knowledge systems so they can incorporate knowledge produced in other institutional sites - in hospitals, schools, industrial plants, government and the like? How can this knowledge be incorporated into metaanalyses by means of semantic publishing markup, tagging and data mining?

6. Disciplinarity and Interdisciplinarity: How does publishing in different discipline areas reflect varied epistemological modes - from the social practices of citation and prepublication review to post-publication circulation? How is intellectual community created? Here, we need to focus on lessons that may be learnt across disciplines for the creation of more resilient forms of knowledge. It will also examine the question of how new and cross-disciplinary knowledge systems emerge.

7. Modes of representation and signification: The digital media present new potentials for knowledge representation. Conventional scholarly publishing has not yet fully realised the multimodal affordances of the new media. What places do websites, video and datasets have in the new media? How might disciplines traditionally represented only by exegesis, such as the arts, media, communications, design and architecture, be 
formally brought into academic knowledge systems? How might they use forms of representation which are closer to their core professional and disciplinary practices?

8. Globalism: Approximately one quarter of the world's universities are in the Anglophone world. However, the vast majority of the world's academic publishing is from academics in Anglophone countries. A more comprehensive, powerful and equitable global knowledge system would reduce this systemic bias. The key question here is how to achieve this without prejudice to intellectual quality. There are also questions about how a more closely integrated global knowledge system would work. The answers here lie in examination of: the role of English as a lingua franca including articles written with a second language speaker's "accent"; developments in machine translation; and the role of knowledge schemas, semantic markup and tagging to assist discovery and access across different languages.

9. Reconfiguring the role of the university: Underlying these research questions is a larger question of the changing role of the university, from a place that supports a relatively closed knowledge system to one that serves more open knowledge architectures. How might a more participatory and inclusive knowledge culture created, in which universities assume an integrating rather than exclusionary role?

10. Conditions of knowledge making for a "knowledge economy": Finally, there is an even larger question: how might renewed academic knowledge systems support a broader social agenda of intellectual risk taking, creativity and innovation? How is renovation of our academic knowledge systems a crucial aspect of meeting the heightened expectations of a "knowledge society"? And what are the affordances of the digital media which may support reform?
If we are to make the most of the new, digital communications media in which the internet plays such a central role, we need to move beyond the question of business models and the binaries of the commercial publishing/ open access debate. In all probability, the resolution of this debate will be found in hybrid models and a genuine pluralism of different solutions for different domains of knowledge creation. Open access publishing is likely to grow, and develop sustainability models based on explicit subsidy by institutions and research funders, and possibly also low cost author publication fees. Commercial publishing needs to reduce its cost structures, and if the big publishers can't, innovative new entrants will. Given that the content selection and review energies are located in the peer community, there is no reason why an academic article can't be sold (on the iTunes model) for $\$ 1$, or an institutional subscription for $\$ 50$. And at the other end of the scale, there is no reason why a research centre or academic department shouldn't put a high price on commercially valuable information, and by this means support its ongoing research and development work. And then there will be hybrid solutions in which some knowledge is made available at no cost, and other knowledge at a price, all in the same space instead of today's bifurcated commercial/non-commercial spaces.

Whatever the models of sustainability that emerge, knowledge systems of the near future could and should be very different from those of our recent past. The sites of formal knowledge validation and documentation will be more dispersed. They will be more global, in the lingua franca of English and also, not necessarily so. The knowledge processes they use will be more reflexive and so more thorough and reliable. Knowledge will be published more quickly. Through semantic publishing, it will be more discoverable and open to aggregation and reinterpretation. There will be much more of it, but it will be much easier to navigate. The internet provides us these affordances. It is our task as knowledge workers to realise the promise of the internet and to create more responsive, equitable and powerful knowledge ecologies. 


\section{REFERENCES}

Benkler, Yochai (2006): The Wealth of Networks: How Social Production Transforms Markets and Freedom, New Haven, Yale University Press.

Bergman, Sherrie S. (2006): "The Scholarly Communication Movement: Highlights and Recent Developments", CoIlection Building, 25, 108-128.

Biagioli, Mario (2002): "From Book Censorship to Academic Peer Review", Emergences: Journal for the Study of Media \& Composite Cultures, 12, 11-45.

Cope, Bill y Kalantzis, Diana (eds.) (2001): Print and Electronic Text Convergence, Melbourne, Common Ground.

Cope, Bill y Kalantzis, Mary (2004): "TextMade Text", E-Learning, 1, 198-282.

Cope, Bill y Phillips, Angus (eds.) (2006): The Future of the Book in the Digital Age, Oxford UK, Chandos Publishing.

Eisenstein, Elizabeth L. (1979): The Printing Press as an Agent of Change: Communications and Cultural Transformation in Early-Modern Europe, Cambridge, Cambridge University Press.

Febvre, Lucien y Martin, Henri-Jean (1976): The Coming of the Book, London, Verson.

Grafton, Anthony (1997): The Footnote: A Curious History, London, Faber and Faber.

Guédon, Jean-Claude (2001): "In Oldenburg's Long Shadow: Librarians, Research Scientists, Publishers, and the Control of Scientific Publishing", Association of Research Libraries, Conference Proceedings.

Kalantzis, Mary (2006): "Changing Subjectivities, New Learning", Pedagogies: An International Journal, 1, 7-12.

Kalantzis, Mary y Cope, Bill (2008): New Learning: Elements of a Science of Education, Cambridge UK, Cambridge University Press.

Recibido: 6 de diciembre de 2007 Aceptado: 15 de enero de 2008
Lessig, Lawrence (1999): Code and Other Laws of Cyberspace, New York, Basic Books.

- (2001): The Future of Ideas: The Fate of the Commons in a Connected World, New York, Random House.

- (2004): Free Culture, New York, Penguin Press.

Linklider, J. C. R. (1965): Libraries of the Future, Cambridge MA, MIT Press.

Martin, Elaine y Booth, Judith (2007): ArtBased Research:A Proper Thesis?, Melbourne, Common Ground.

O'Reilly, Tim (2005): "What Is Web 2.0? Design Patterns and Business Models for the Next Generation of Software".

Ong, Walter J. (1958): Ramus, Method and the Decay of Dialogue, Cambridge MA, Harvard University Press.

Peters, Michael A. (2007): Knowledge Economy, Development and the Future of Higher Education, Rotterdam, Sense Publishers.

Raymond, Eric (2001): The Cathedral and the Bazaar: Musings on Linux and Open Source by an Accidental Revolutionary, Sebastapol CA, O'Reilly.

Rose, Mark (1993): Authors and Owners: The Invention of Copyright, Cambridge MA, Harvard University Press.

Stallman, Richard (2002): Free Software, Free Society, Boston MA, GNU Press.

Stanley, Christine A. (2007): "When Counter Narratives Meet Master Narratives in the Journal Editorial-Review Process", Educational Researcher, 36, 14-24.

Waters, Lindsay (2004): Enemies of Promise: Publishing, Perishing and the Eclipse of Scholarship, Chicago, Prickly Paradigm Press.

Williams, Sam (2002): Free as in Freedom: Richard Stallman's Crusade for Free Software, Sebastapol CA, O'Reilly.

Willinsky, John (2006): The Access Principle: The Case for Open Research and Scholarship, Cambridge MA, MIT Press. 